\title{
Access and Benefit Sharing Models of Biodiversity Conservation in International and Comparative Law Perspective
}

\author{
M.Z.M.Nomani ${ }^{1}$, Faizanur Rahman ${ }^{2}$, Mohammad Rauf ${ }^{3}$, Saif A. Khan ${ }^{4}$ \\ ${ }^{1}$ Professor, Faculty of Law, Aligarh Muslim University, Aligarh-202002(U.P./INDIA) \\ ${ }^{2}$ Assistant Professor, Faculty of Law, Jamia Millia Islamia University, New Delhi-110025(INDIA) \\ ${ }^{3}$ Assistant Professor, Faculty of Law \& Islamic Studies, Maldives National University, Male (Maldives) \\ ${ }^{4}$ Research Scholar, Aligarh Muslim University, Aligarh-202002(U.P./INDIA)
}

Correspondence Author: Md. Zafar Mahfooz Nomani, 1Professor, Faculty of Law, Aligarh Muslim University, Aligarh-202002(U.P./INDIA) Email:zafarnomani@rediffmail.com

Mobile No. +91-9897211417

Received date: 22 September 2019, Accepted date: 22 January 2020, Online date: 22 March 2020

Copyright: (C) 2020 Md. Zafar Mahfooz Nomani. This is an open-access article distributed under the terms of the Creative Commons Attribution License, which permits unrestricted use, distribution, and reproduction in any medium, provided the original author and source are credited.

\begin{abstract}
The Access and Benefit Sharing (ABS) models of biodiversity conservation in international and comparative law perspective is mandated by the Convention on Biological Diversity (CBD), 1992; Bonn Guidelines On Access To Genetic Resources and The Fair and Equitable Sharing of Benefits (FESB) Arising Out of Their Utilization, 2001 and Nagoya Protocol on Access to Genetic Resources and the FESB Fair and Equitable Sharing of Benefits Arising from their Utilization, 2010. These laws are meant for biodiversity conservation, sustainable use, fair and FESB which in turn obligate the member states to swing into action for devising ABS law and policy. The objective of international and comparative ABS regime abjures synergy with environmental sustainability, intellectual property (IP) and sui generis system. The results of the study reveal that ABS law represents municipal traditional knowledge (TK) system deeply reflecting on communitarian environmental management and IPR system. The critical analysis of prevalent doctrines on international, comparative and Indian biodiversity conservation laws and policies in qualitative and empirical research methods reveals a monistic legal order with variation in the national specific context. The study leads to the conclusion that the ABS regime discerns a competing set of interests of biodiversity resources, sustainable development, climate change, and environmental justice delivery. Moreover, the biological diversity legislation in general and ABS laws and policies, in particular, is attuned to FESB in monetary and non-monetary terms to nurture indigenous inspiration for sustainable use and biodiversity conservation in natural and applied scientific studies.
\end{abstract}

Keywords: Bio-Diversity Conservation, Genetic Resources, Intellectual Property, Traditional Knowledge, Biodiversity Register, Biodiversity Governance

\section{INTRODUCTION}

The cardinal goal of Convention on Biological Diversity (CBD), 1992 is to promote sustainable development, by stressing that the conservation of biological diversity is a common concern of mankind. Article 1 of the $C B D, 1992$, envisages three significant objectives such as sovereignty over natural resources, sustainable use and, equitable ABS arising from components of biodiversity [1]. The CBD recognizes the significance of traditional knowledge-driven innovations of indigenous communities relevant to the ABS and FEBS [2]. These objectives are reflected in Articles 6 to 20 of CBD which enjoined member state to develop national legislation for the establishment of an ABS system based around an international certificate of the original source and legal provenance [3]. The following Chart underpins broad themes for ABS of genetic resources and biodiversity. 


\section{ABS Provision}

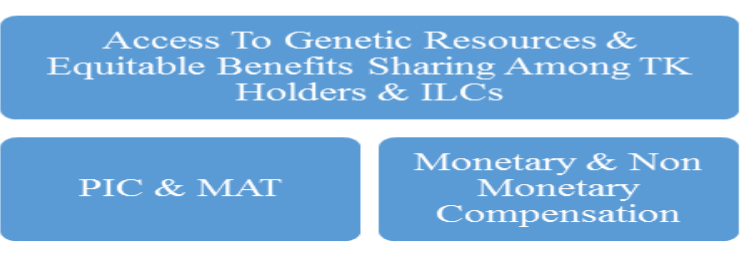

In Situ \& Ex Situ Conservation

Figure -I: Key ABS Provisions under CBD, 1992

The Plant Genetic Resources (PGRs) is considered 'legacy of humankind' and was shared uninhibitedly among countries till the promulgation of CBD, 1992[4]. One of the contentious issues among the objectives of CBD is FESB of benefits and regulation of the access to biodiversity, TK management and protection of indigenous intellect [5]. The ABS lawmaking has to combine with the legislative ethos of environmental law and IP laws laced within principles of administrative law to afford protection to grass-root innovators [6].

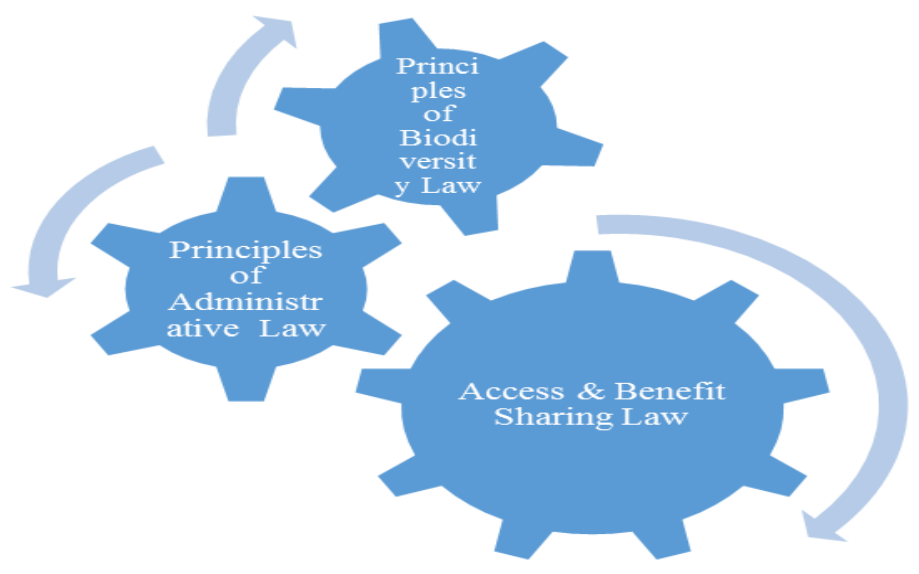

Figure -II: Interaction of Environmental Law, IP Law \& Administrative Law in ABS Law

The ABS is governed by the CBD, 1992, Bonn Guidelines 2001 and Nagoya Protocol, 2009 internationally and Biodiversity Act, 2002; Biodiversity Rules, 2004, ABS Guidelines, 2014 in the Indian context. ABS provisions are designed for equitable benefits sharing of access to genetic resources among TK holders and indigenous and local communities (ILCs) as per Bonn Guideline, 2001[7]. The ABS model can be in situ and ex-situ, monetary and nonmonetary commercial and non-commercial to incentivize grass-root innovation and knowledge through Competent National Authorities (CNAs). The Nagoya Protocol, 2009 ordains the inclusion of every stakeholder involved in the development of a product like breeders, farmers, tribes or indigenous communities in the ABS process [8]. The $C B D, 1992$ affirms that nations have sovereign rights over their own biological resources but at the same time, balance competing priorities of economic and sustainable development in the ABS framework [9]. The scientific community has been of the view that bureaucratic impediments placed in access to biological and genetic resources under CBD are retarding in reaping the rewards of biotechnological innovations and incentives. This is buttressed by Indian ABS provisions under the Biological Diversity Act, 2002, which requires government approval and payment of US $\$ 200$ application fee to access biological associated knowledge for research [10]. These laws obstruct biodiversity-related research and blur the distinction between commercial and conservation sciences. According to an estimate, it is established that the commercial returns from ABS in many CBD compliant countries remain marginal to their national biodiversity conservation budgets. The paper takes a legal stance on ABS models of biodiversity conservation mandated under in international and comparative law and its adoption under Indian legal regime.it also examines the legal efficacy of the biodiversity conservation strategy vis-à-vis ABS regime prevalent in people's biodiversity register (PBR) and digitization of traditional knowledge property in the Indian context. 
The material and method employ doctrinal and empirical holism bordering the foundational values of $C B D, 1992$ from a comparative law perspective. The paper scrutinizes Indian, Australian, Costa Rican, and Philippines ABS case studies to have a rounded view across the continent [11]. The objectives of CBD principles in the development of the ABS system at Indian jurisdictions are examined in qualitative and quantitative research [12]. Indian ABS case studies, Peoples' Biodiversity Register (PBR) and other methods of benefit-sharing tools and instruments and modules of the TK protection system are undertaken in statistical methods of relative frequency and index, statistical Relation and regression analysis. This is helpful in our understanding of the biodiversity law discourse in the pragmatic framework. The corpus of ABS laws and policies handed down by the international environmental laws and intellectual property laws are culled out and applied in Indian, Australian, Costa Rican, South African and Philippines models to gauge the policies and precept gap [13]. The study combines the ABS model based on in situ and ex-situ conservation, commercial and non-commercial and monetary and non-monetary to reflect the feasibility and affordability in Indian biodiversity legal regime. The special care has been exercised in assessing the Indian model of ABS in pre and post CBD, 1992 right from the Kani Tribe model of ABS phase (i.e., 1979 to 2018) from the primary data of National Biodiversity Authority (NBA) in India in empirical holism.

\section{RESULTS}

ABS has become the centerpiece of biodiversity-related legislation in its administrative as well as a legal framework as evident from Table-I and II [14]. The comparative context of some countries evidences progressive laws on ABS while others have merely amended existing biodiversity laws to give partial recognition to ABS components. It is generally said that the ideological moorings of Trade-Related Aspects of Intellectual Property Rights (TRIPS) Agreement, 1995 tilts towards Organisation of Economic Cooperation and Development (OECD) model of developed western countries, whereas the socio-economic differences between India and the eastern world are perceptible and the laws which are beneficial for the West is not necessarily beneficial for the eastern world in ABS regime [15]. Indian ABS model advocated for biodiversity-related intellectual property regimes having strong leanings towards a community-oriented regime to foster growth and innovation [16]. Before we dwell upon the Indian ABS, it seems worthwhile to have a comparative look towards the Philippines, Costa Rican and Australian model of ABS to draw lessons for refurbishing the Indian model.

B. Philippines ABS Model: The Philippines ABS Model draws its genesis to not only CBD, Bonn and Nagoya norms but to the Philippine Constitution, 1987. It recognizes the CBD principle of sovereignty over natural resources by enunciating that all lands of the public domain, water, minerals, fisheries, forests, wildlife, flora and fauna, natural resources are owned by the State for disposition, development, and utilization (Section 2, Article XII) [17]. In line with constitutional mandate and compliance of $C B D, 1992$ the State promulgated Executive Order No. 247 namely Regulatory Framework for Prospecting of Biological \& Genetic Purposes, 1995 for sustainable development of biological and genetic resources (Executive Order No. 247, 1995) through its nodal agency known as Department of Environment and Natural Resources (DENR) by an Administrative Order No. 96-20[18]. The Philippine's ABS regulation under Executive Order No. 247 has four essential elements outlined in the chart given as under:

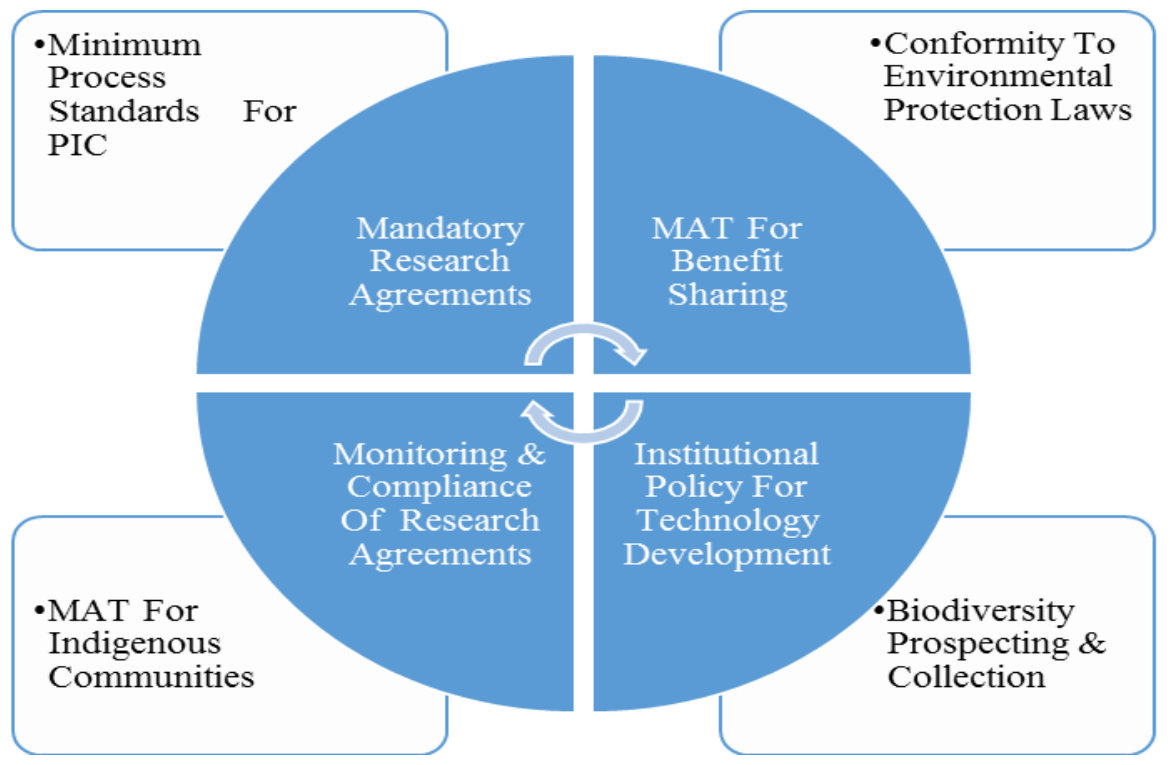




\section{Figure 3: Basic Features of Philippine's ABS Regulation}

The protection of TK supplements this by the enactment of the Indigenous Peoples' Rights Act, 1997[19]. Section 34 of the Act confers recognition of the full ownership and control and protection of their cultural and intellectual rights. Such people are entitled to control, develop and protect their sciences, technologies and cultural manifestations. This affords protection to seeds derivatives, traditional medicines and health practices. The vitality of medicinal plants, animals and minerals are also bestowed to indigenous people. Thus their rights to knowledge systems and practices, properties of fauna and flora, traditions, literature, designs and visual and performing arts are also encompassed under Section 34 of the Act [20]. Section 35 fortifies the access to biological resources, indigenous knowledge system, conservation, utilization, and enhancement of genetic resources. Such resources shall be allowed to be accessed within ancestral lands by PIC and customary laws indigenous community [21]. The implementing mechanism of the Indigenous Peoples' Rights Act, 1997 is governed by CAN known as DENR [22].

C. Costa Rican ABS Model: Costa Rica occupies only $0.01 \%$ of the global territory and posses almost $6 \%$ of the known species of the tropical zone of the American continent. When being compared to the other countries famous for biological diversity, Costa Rica's concentration of biological resources becomes evident by the fact that out of 500000 species, 87000 have been found there only. Over $79 \%$ of these beings are arthropods. More than 10000 Plants species, $98 \%$ of vertebrates (excluding fish), $60 \%$ of fish and $79 \%$ of arthropods are identified [23]. This rich biodiversity is regulated by Merck (Multinational American Pharmaceuticals Company)-INBIO (Asociacion Instituto Nacional de Biodiversidad) Agreement, 1991 ABS Agreement across stakeholders. Merck has a right to research exclusively on biological resources and share the benefits arising out of that access with INBIO, Costa Rican government and the respective stakeholders [24]. The Table -I: represents the characteristic features of Costa Rican ABS as under:

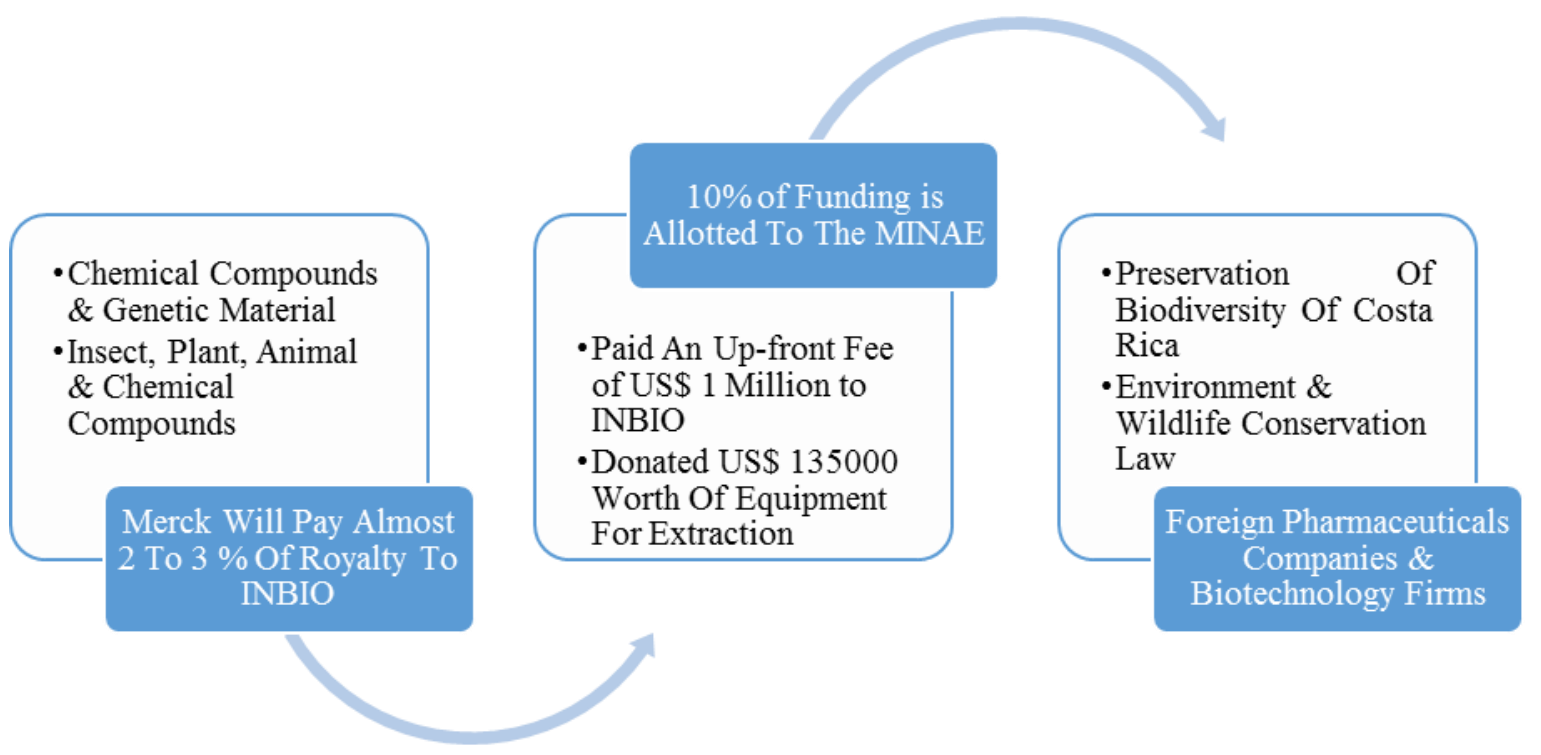

\section{Figure 4: Characteristic Features of Costa Rican ABS Model}

The characteristic feature of the Costa Rican model envisages a minimum of $10 \%$ of funding to the exchequer of the Costa Rican Ministry of Environment and Energy (MINAE). The agreements brought a lot of changes in IPR related legislation as Costa Rican national assembly abdicated the responsibility of negotiating agreements with Multinational Corporation [25]. Access to Costa Rica's genetic material would be ensured to foreign pharmaceuticals companies and biotechnology firms. The ABS laws, policies and the institutional mechanism are backed by $2 \%$ to $3 \%$ royalty from 20 products of Merck. Merck will pay $10 \%$ of the prospecting fee to the Costa Rican government as well as $50 \%$ of the royalty too. The MINAE received half of the amount paid by Merck to INBIO and is using that money on maintaining the marine park at coco island, training the Costa Rican scientists and field collectors and lush biodiversity of Costa Rica, gathering almost 5000 insects and 50 plant species each month. Ten percent of the total initial one million dollars and half of the royalties will be spent on the conversation of biodiversity through MINAE natural resources. The other fifty percent will be spent 
on biodiversity through the discretion of the board of directors of IN BIO. The Merck (Multinational American Pharmaceuticals Company)-INBIO (Asociacion Instituto Nacional de Biodiversi dad) Agreement, 1991 is a landmark ABS model in Costa Rica is hailed as an instrument of sustainable development and biodiversity conservation.

D. Australian ABS Model: Australia is one of the first countries which developed legislation in compliance with Articles 3 and 15 of CBD, 1992; Bonn Guidelines, 2001 and Nagoya Protocol, 2009. Australia's wealth is economically dependent on the exports of agriculture and natural resources, and its ABS system is based on the assumption that genetic resources-related research and development are an essential ecosystem service as it produces economic outcomes that increase the diversity of the environment and contribute to its conservation. Australia's South Western Pacific Rim, ABS legislation is in compliance with PIC, MAT of $C B D, 1992$ and bonded in the Anglo-Saxon heritage of the United Kingdom and the United States and replicated in Canada, New Zealand and India [26]. Australia ABS is a very experienced nation in terms of the $\mathrm{ABS}$ regulations and has developed one of the most advanced and efficient legislation regarding biodiversity. The basic framework is drawn from Section 301 of Environment Protection and Biodiversity Conservation Act (EPBC), 1999 and supplemented by Part 8-A of EPBC Regulations, 2000 in giving effect to the primary objectives of EPBC depicted in flow chart given below [27].

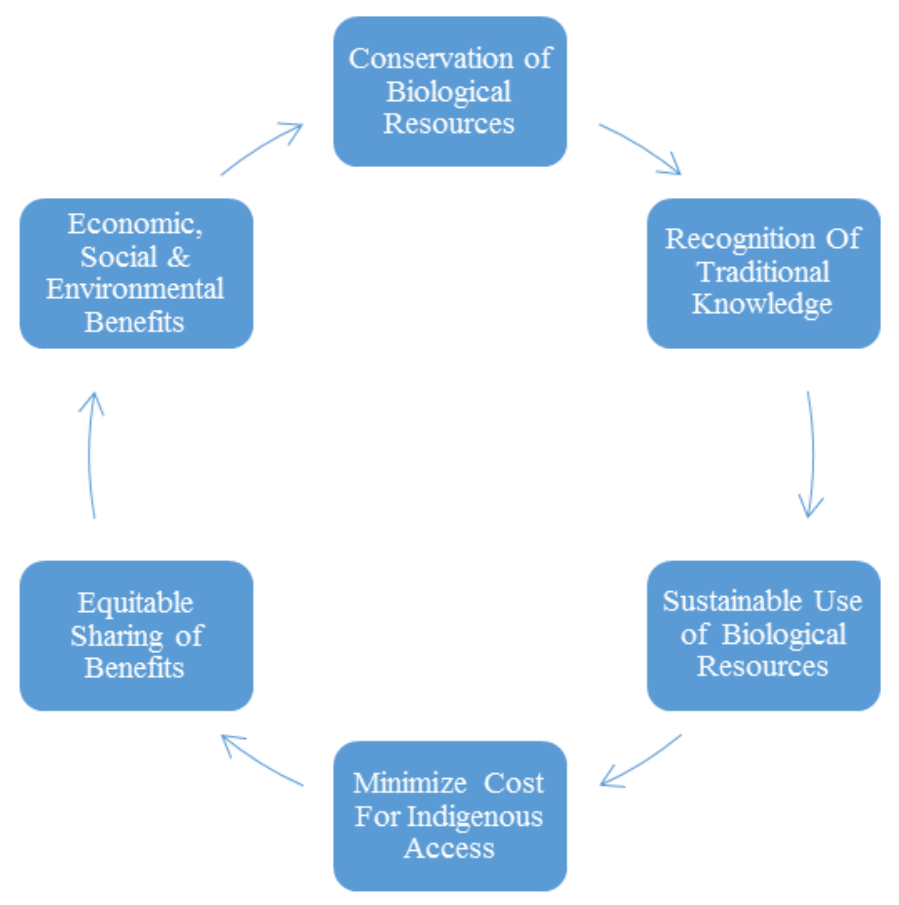

Figure 5: ABS Objectives under the Australian EPBC, 1999

The Australian ABS Agreement with the Secretariat of the Pacific Regional Environment Programme (SPREP) provided EUR 250,000 for specific projects and activities in the Pacific region and Oceania Biodiscovery Forum in Brisbane in 2012. To this end, the perusal of comparative ABS legislations of the Philippines, Costa Rica and Australia need to replicate in other jurisdictions to refurbish domestic ABS law and policy [28].

\section{DISCUSSION}

It is under this backdrop that we wish to explore the nature and characteristic of Indian ABS laws. The Indian parliament has passed national biodiversity law, rule and guideline to implement Convention's mandate following federally sound principles of biodiversity governance [29]. Therefore ABS and MTA need an understanding of differences and similarities between by-products and derivatives of bioprospecting because countries generally consider the inclusion of 'derivatives' within the definition of by-products [30]. This should be clarified from the fact that a by-product can be taken from biological and genetic resources such as hides, antlers, feathers, fur, internal organs, roots, trunks, branches, leaves, stems, flowers and the like, including compounds indirectly produced in a biochemical process or cycle[31]. On the other hand, a derivative can be extracted from a biological and genetic 
resource such as blood, oils, resins, genes, seeds, spores, pollen and the like taken from or modified from a product. Similarly, unmodified by-products and relationship with TK will remain unclear in terms of herbal medicine [32].

E. Indian ABS Model: India is one of the CBD compliant and megadiverse regions around the world have three major biodiversity hotspots in India known as the Himalayas, Western Ghats, Indo-Burma region 14 Biosphere Reserves, 25 Ramsar sites and About 605 protected areas[33].Historically the absence of ABS legislation has resulted in almost unlimited access to India bioresources to research and development abroad and for commercial and industrial exploitation. As a result, the ABS was not shared by the country as a whole, including the indigenous holder of traditional knowledge [34]. The abundance of genetic and other biological resources in these areas are well known.

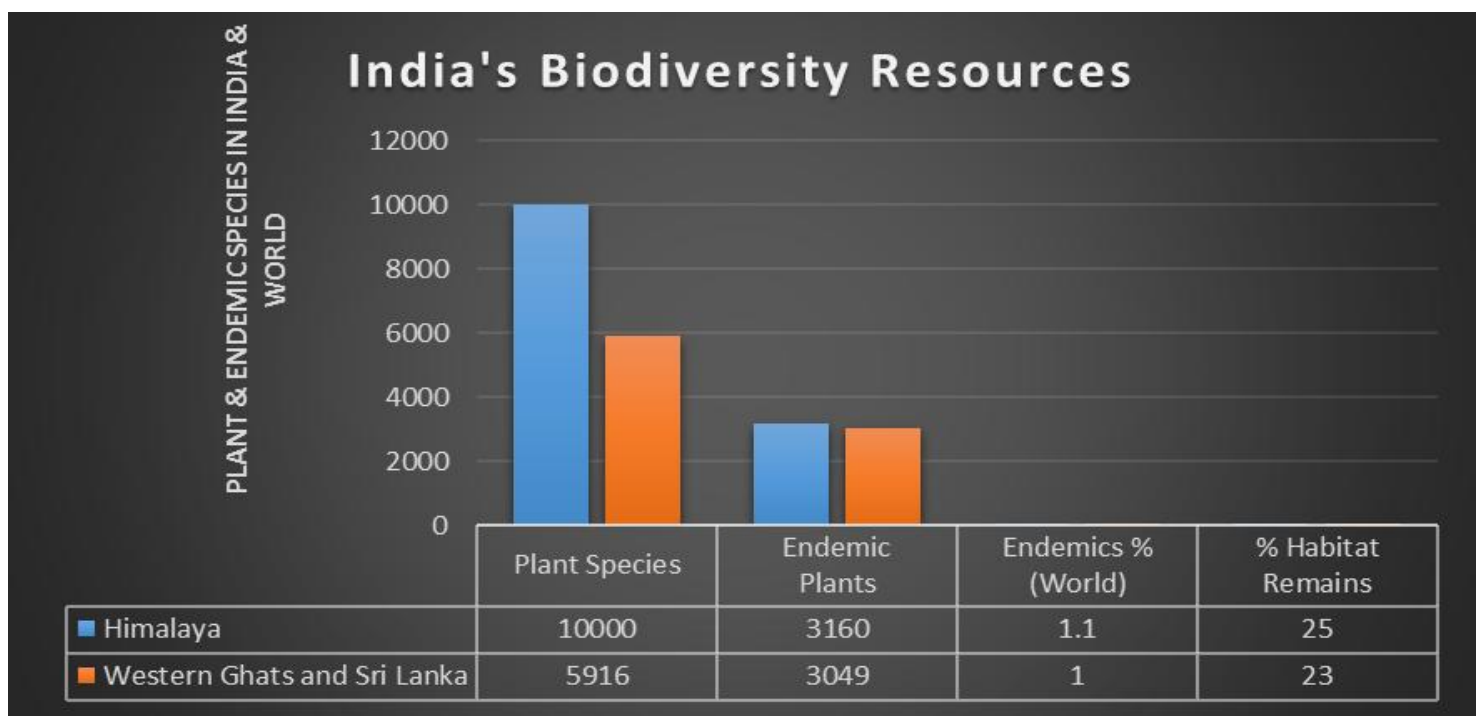

\section{Chart 1: Biodiversity Hotspots In India}

According to various estimates, it is predicted that the potential value of the genetic resources in the market obtained through biological diversity is somewhere around US\$ 800 and US\$ 1 trillion [35]. This ABS legislation is guided by the Biodiversity Act, 2002; Biodiversity Rules 2004, ABS Guidelines, 2014[36]. The financial strength of the Biodiversity Management Committee (BMC) under Section 43 of the Biodiversity Act, 2002 could only be established through the realization of fees for accessing genetic resources based on the economic valuation of the bio-resources and nurturing sustainable livelihood of local communities [37].

Table 1: Establishment of Biodiversity Management Committee (BMC) for ABS Approval 2013-2017

\begin{tabular}{|l|l|l|l|c|}
\hline States & $\mathbf{3 1 . 0 3 . 2 0 1 3}$ & $\mathbf{3 1 . 0 3 . 2 0 1 4}$ & $\mathbf{3 1 . 0 3 . 2 0 1 5}$ & $\mathbf{0 8 . 0 8 . 2 0 1 7}$ \\
\hline Nagaland & 10 & 10 & 10 & 10 \\
\hline Odisha & - & - & 230 & 1036 \\
\hline Punjab & 54 & 55 & 55 & 69 \\
\hline Rajasthan & 22 & 26 & 31 & 95 \\
\hline Sikkim & 7 & 7 & 13 & 27 \\
\hline Tamil Nadu & 13 & 13 & 16 & 16 \\
\hline Telangana & - & - & 710 & 2402 \\
\hline Tripura & 80 & 179 & 217 & 361 \\
\hline Uttar Pradesh & 8 & 9 & 32 & 106 \\
\hline Uttarakhand & 598 & 734 & 751 & 907 \\
\hline West Bengal & 81 & 81 & 176 & 205 \\
\hline India & $\mathbf{3 3 4 3 7}$ & $\mathbf{3 4 1 3 5}$ & $\mathbf{3 7 7 6 9}$ & $\mathbf{6 2 5 0 2}$ \\
\hline
\end{tabular}

Source: Lower House of Parliament Unstarred Question No. 1547, dated on 08.12.2015 \& Question No. 3498, Dated on 08.08.2017

The equitable sharing of benefit is defined by Section 21 of the Biodiversity Act, 2002 with the clear intent of regulating PIC and MAT as a CBD oriented regime. The results interpreted in the tables above are based on the statistical methods of correlation and relative frequency and indexing in depicting the impact and assessment [38]. 
The post-CBD phase heralded reforms in environmental as well as IP laws especially plant variety and trade secrets of India in the TK framework with the intent of digitization of knowledge further boosting to the development of international and comparative ABS law in short and long term biodiversity action plans [39].

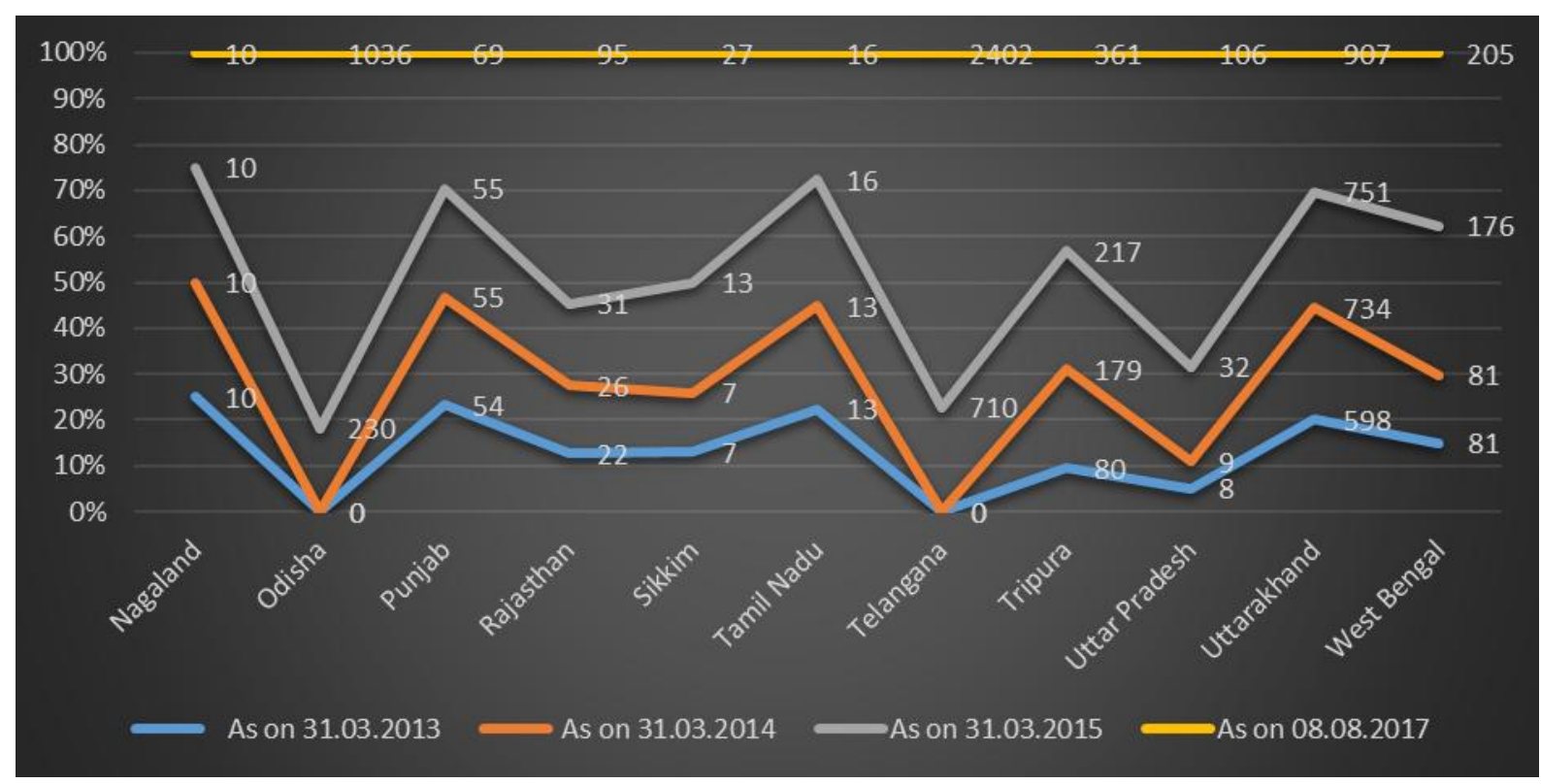

\section{Chart 2: Establishment of (BMC) for ABS Approval 2013-2017}

One such manifestation is people's biodiversity register (PBR) under Rules 22(2) and 22(6) of Biodiversity Rule, 2004 which is based on MAT, PIC, sovereignty over natural resources, and community-oriented IPR regime which is community-oriented TK driven in approach[40]. The unintended impact of the CBD regime on physical and biological research outweighs benefits or detriment needs to be analyzed in the pragmatic framework[41].

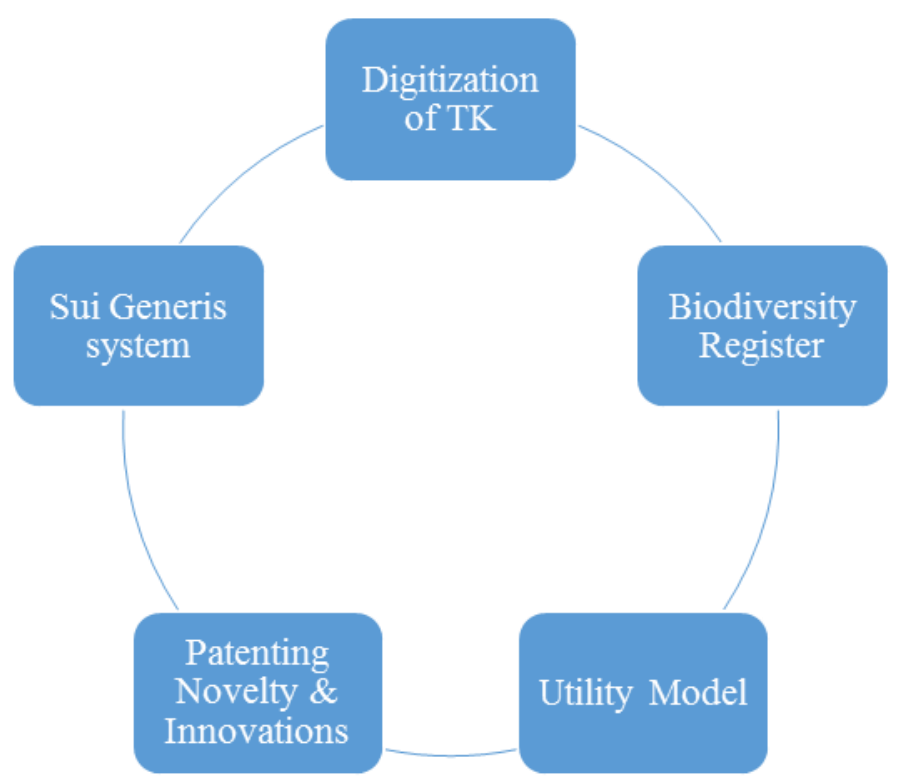

Figure 6: Characteristic Features of Indian ABS

The preparation of PBR as a participatory process identified a wide range of concerns and priorities for IP protection to biodiversity resources. In order to buttress the point, a reference to Tropical Botanic Garden and Research Institute, Kerala Forest Institute and ABS Agreement with Kani Tribe of Kerala state can be made [42]. 
Table 2: Peoples’ Biodiversity Register Prepared By Indian States [As On 18/02/2019]

\begin{tabular}{|l|l|r|r|}
\hline S.No. & State & PBR & Relative Frequency \\
\hline & Karnataka & 1777 & 27.55 \\
\hline & Gujarat & 1126 & 17.46 \\
\hline & Kerala & 892 & 13.83 \\
\hline & Madhya Pradesh & 890 & 13.80 \\
\hline & Tripura & 431 & 6.68 \\
\hline & Uttar Pradesh & 325 & 5.04 \\
\hline & Telangana & 220 & 3.41 \\
\hline & West Bengal & 150 & 2.33 \\
\hline & Uttarakhand & 124 & 1.92 \\
\hline & Andhra Pradesh & 100 & 1.55 \\
\hline & Maharashtra & 100 & 1.55 \\
\hline & Assam & 92 & 1.43 \\
\hline & Odisha & 87 & 1.35 \\
\hline & Arunachal Pradesh & 43 & 0.67 \\
\hline & Meghalaya & 30 & 0.47 \\
\hline & Manipur & 22 & 0.34 \\
\hline & Jharkhand & 14 & 0.22 \\
\hline & Punjab & 11 & 0.17 \\
\hline & Himachal Pradesh & 6 & 0.09 \\
\hline & Mizoram & 5 & 0.08 \\
\hline & Sikkim & 4 & 0.06 \\
\hline & Total & $\mathbf{6 4 9}$ & $\mathbf{1 0 0}$ \\
\hline
\end{tabular}

Source: http://nbaindia.org/content/105/30/1/pbr.html [Logged on 1.3.2019]

India is a federal union comprising 28 states and 8 union territories, for a total of 36 entities. However, the above table shows that only 21 states have taken the initiative of preparation of PBR under biodiversity law and ABS. The relative frequency and index show significant variation in terms of state readiness and response. Karnataka has taken the leading position, which almost the one-fourth of all the states taken together in India. The state of Karnataka also developed a unique system of PBR under Karnataka Biodiversity Conservation Order in 1996[43]. The table is arranged from the highest to lower order, but the most significant state in area Madhya Pradesh and Uttar Pradesh comes under fourth rank and sixth rank. The Kerala and Tripura are relatively small states but have taken the lead in initiating PBR. There are states like Andhra Pradesh and Maharashtra which has merely reached 100 PBRs despite their richness in biodiversity and area. The states like Arunachal Pradesh, Meghalaya, Manipur, Jharkhand and Punjab Relative index is below 50 PBRs. The frequency Himachal Pradesh, Mizoram and Sikkim are traditional knowledge repository and biodiversity-rich states, but their performance is abysmally low even less than 10 PBRs. The Comparative state-wise national average is 6449 PBRs as per the record of NBA documented as on 18/02/2019. 


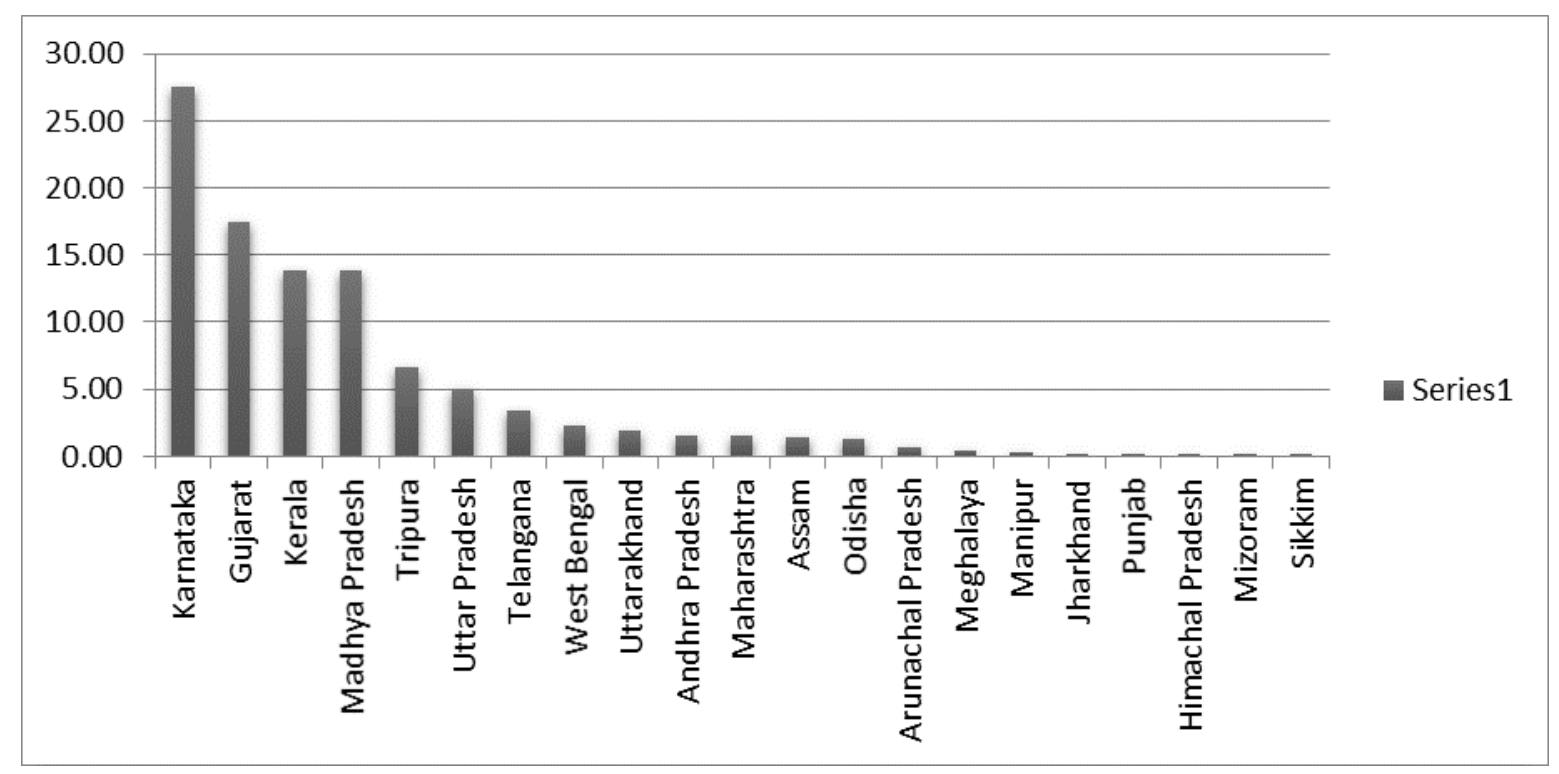

\section{Chart 3: PBR Prepared By Indian States [As On 18/02/2019]}

The access to any biological resource for commercial use is based on approval of the NBA under Form I, Form II, Form III, Form IV and Section 3(2) of Biodiversity Act, 2002. Under this background, it becomes imperative to have a look at the role of the NBA in granting approval to ABS during 2005-2018[44].

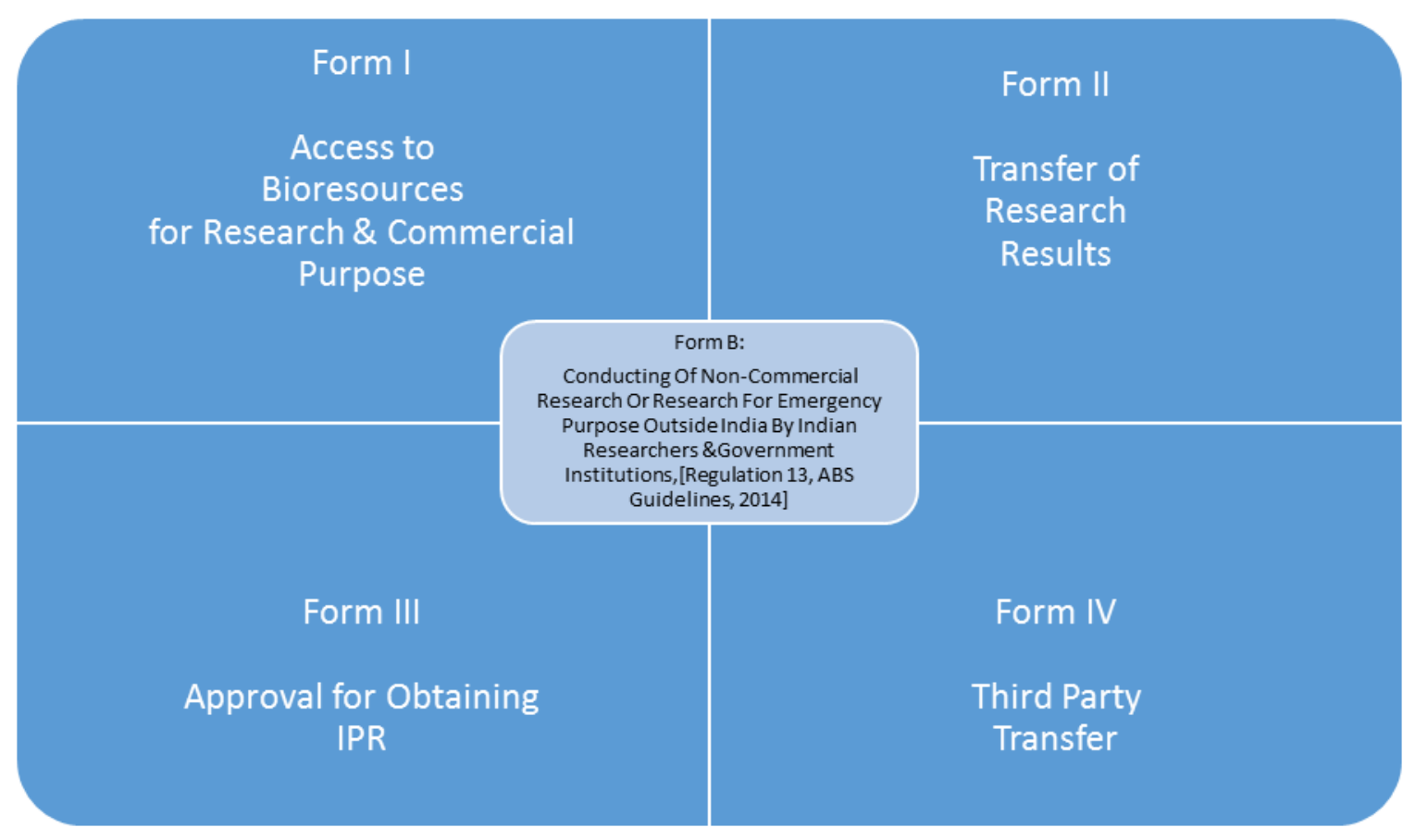

Figure 7: ABS Approval Process By NBA under Biodiversity Act, 2002

Chapter II of the Biodiversity Act, 2002 is centred on the regulation of access to traditional knowledge and biological resources. It regulates access for foreigners, non-resident Indians, and Indian citizens. 
Table 3: Approval of ABS Applications By NBA During 2006-2018

\begin{tabular}{|l|l|l|l|l|l|l|}
\hline Year & Form I & Form II & Form III & Form IV & Form B & Total \\
\hline 2006 & 4 & 1 & 0 & 2 & 0 & 7 \\
\hline 2007 & 5 & 3 & 12 & 6 & 0 & 26 \\
\hline 2008 & 4 & 4 & 21 & 6 & 0 & 35 \\
\hline 2009 & 2 & 1 & 9 & 1 & 0 & 13 \\
\hline 2010 & 3 & 1 & 4 & 1 & 0 & 9 \\
\hline 2011 & 1 & 2 & 6 & 0 & 0 & 9 \\
\hline 2012 & 1 & 0 & 8 & 7 & 0 & 16 \\
\hline 2013 & 1 & 0 & 14 & 2 & 0 & 17 \\
\hline 2014 & 19 & 0 & 22 & 1 & 0 & 42 \\
\hline 2015 & 31 & 1 & 51 & 2 & 7 & 92 \\
\hline 2016 & 36 & 4 & 127 & 0 & 15 & 182 \\
\hline 2017 & 36 & 2 & 246 & 1 & 31 & 318 \\
\hline 2018 & 39 & 1 & 88 & 1 & 11 & 141 \\
\hline Total & $\underline{\mathbf{1 8 3}}$ & $\underline{\mathbf{2 0}}$ & $\underline{\mathbf{6 0 8}}$ & $\underline{\mathbf{3 0}}$ & $\mathbf{6 4}$ & $\mathbf{9 0 4}$ \\
\hline
\end{tabular}

This is to be remembered that the NBA was established in 2003, but the ABS approval process initiated only in 2005. It is evident from the records of the NBA that 904 applications are approved until $20^{\text {th }}$ Dec.2018.

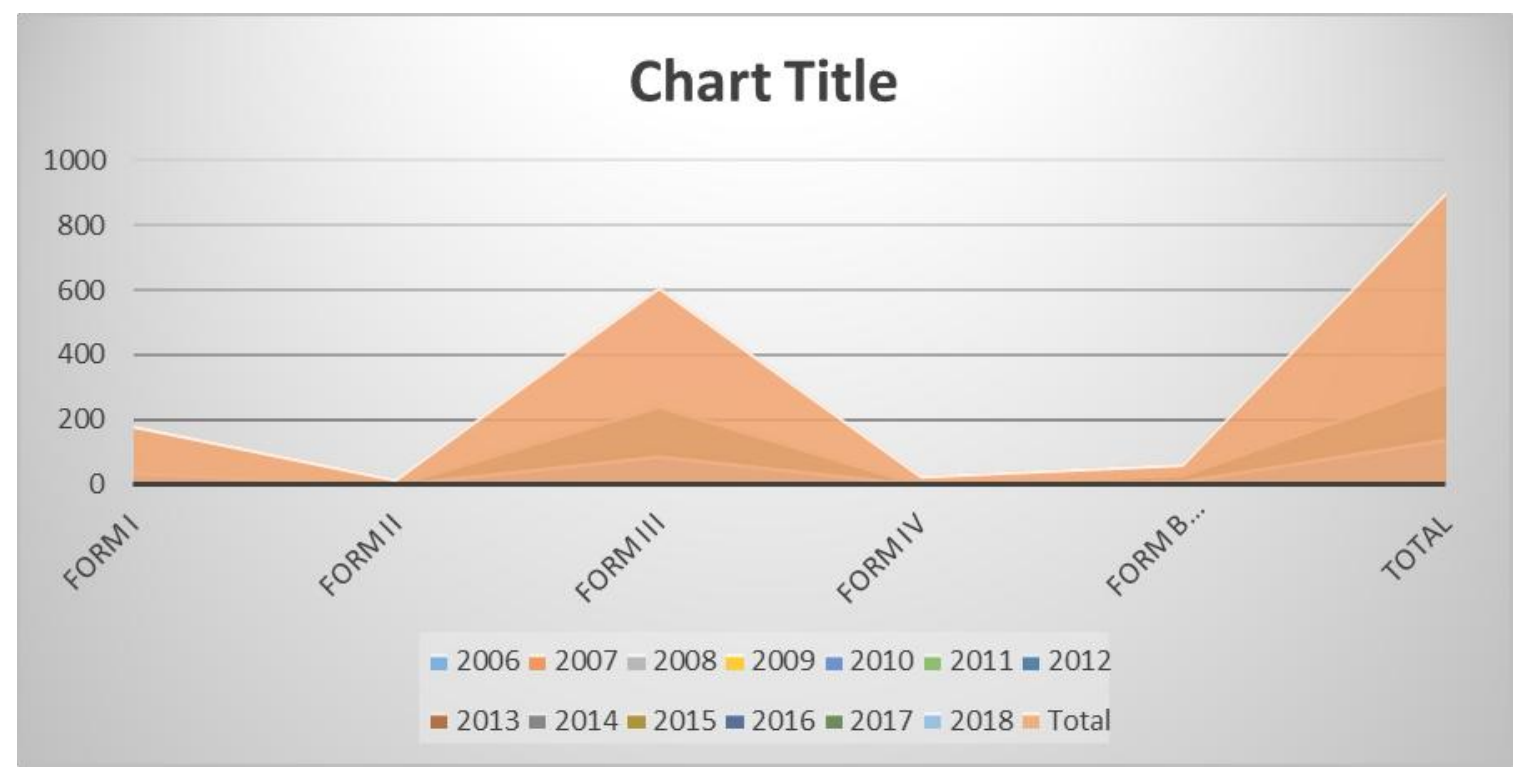

Chart 4: Approval of ABS Applications By NBA During 2006-2018

The biological resources are rich in India and can contribute immensely if regulated by proper legislation and government agencies. It can also help in the development of technology and indigenous pharmaceutical as well as the other industries of India.

\section{CONCLUSION}

The adoption of Bonn Guidelines, 2001 and Nagoya Protocol, 2009 under CBD, 1992 is praiseworthy however the execution is troublesome concerning the productive system of the utilization of genetic resources; recognition of the sovereignty of states over biological resources and the equitable sharing of the benefits among the community. According to the CBD Secretariat, to date, only 60 countries have domestic laws and regulations for fair and equitable sharing of benefits. Even after two decades of the implementation of CBD, a large number of Parties to the Convention continue to face challenges in the adoption and implementation of functional national ABS laws and policies. That is why the negotiations between developed and developing countries have never been consensual. The ABS models of IPR under Convention, Guidelines, and Protocol threw challenges and opportunities for the Indian 
legal policymakers for honing out a strategy for ABS legislation. The regulation of ABS was one of the sought after priorities because biodiversity comes under the territorial boundaries of the nation. It cast a solemn responsibility on the state $\mathrm{s}$ to provide a legal framework of benefits sharing of biodiversity should be based on equity, fairness, and non-discrimination. The Indian government has sufficient resilience and exuberance in developing an indigenous model by administrative, legislative and participatory regimes. At the same time, ABS regulations should not be very restrictive and stringent regulations based on delay and latches. There is an urgent need for judicious management of biodiversity resources on multi stakeholding basis. This will foster biodiversity heritage and hotspot alongside the reward-return incentive-based ABS with communitarian values synergized with CBD, 1992 and TRIPS Agreement, 1995 across the globe and India.

\section{Conflict of interest No}

\section{Acknowledgment}

The correspondence author would like to acknowledge the Indian Council of Social Science Research, New Delhi for its funding of Minor Research Projects on Role of International Biodiversity Law in Developing Legal Framework for Access and Benefit Sharing (ABS) Regime in India 2019-20.

\section{Ethical clearance No \\ REFERENCES}

[1] Robinson, D. F. (2015). Biodiversity, Access, And Benefit-Sharing: Global Case Studies. Routledge.

[2] Morgera, E., Tsioumani, E., \& Buck, M. (2014). Unraveling the Nagoya Protocol: A Commentary On The Nagoya Protocol On Access And Benefit-Sharing To The Convention On Biological Diversity. Martinus Nijhoff Publishers.

[3] Smith, D., Hinz, H., Mulema, J., Weyl, P., \& Ryan, M. J. (2018). Biological control and the Nagoya Protocol on access and benefit-sharing-a case of effective due diligence. Biocontrol science and technology, 28(10), 914-926.

[4] Lettington R.J. \& Mwanyiki, S., (2006).Case Studies on Access and Benefit Sharing, International Plant Genetic Resources Institute, Rome, Italy.

[5] Nomani, M.Z.M. (2010). Access and Benefit Sharing Models of Intellectual Property Rights under Biological Diversity Convention and Bonn Guidelines: A Critical Appraisal under Indian Perspective. Journal of the Faculty of Juridical Sciences, II, 91-106.

[6] Amirmahmoudi, A., \& Nomani, M.Z.M. (2019). South African Model of Access \& Benefit Sharing \& Its Implications For India', International Journal of Law, 5(2),60-64.

[7] Tsioumani, E. (2018). Beyond access and benefit-sharing: Lessons from the law and governance of agricultural biodiversity. The Journal of World Intellectual Property, 21(3-4), 106-122.

[8] Kamau, E.C., Fedder, B. \& Winter, G., (2010). The Nagoya Protocol On Access To Genetic Resources And Benefit Sharing: What Is New And What Are The Implications For Provider And User Countries And The Scientific Community. Law, Environment, and Development Journal 6(3),246 [Available at http://www.leadjournal.org/content/10246.pdf]

[9] Dutfield, G., (2004). Intellectual Property, Biogenetic Resources \& Traditional Knowledge, Earthscan, London.

[10] Pethiyagoda R., (2004). 'Biodiversity Law Has Had Some Unintended Effects', Nature 429,129.

[11] Maxwell, J.A. (2005). Qualitative Research Design: An Interactive Approach, Sage Publications, London.

[12]Molinyawe, N.M. (2019). The Philippines' Approach to Access \& Benefit Sharing for Genetic Resources \& Indigenous Knowledge, [http://www.biodiversityasia.org/books/abs/Chapter\%2012.pdf logged on 1.3.2019]

[13] Nomani, M.Z.M. \& Rauf,M. (2019). Legal Policy For Bio Prospecting of Natural Resources In India. Indian Journal of Environmental Protection, 39(11): 1009-1015.

[14] Mugabe J., et al., (1996). Managing Access to Genetic Resources: Towards Strategies for Benefit Sharing. African Centre for Technology Studies, Nairobi.

[15] WIPO, (2004). Genetic Resources: Draft Intellectual Property Guidelines for Access \& Equitable BenefitSharing, Intergovernmental Committee on Intellectual Property and Genetic Resources, Traditional Knowledge. WIPO/GRTKF/IC/7/9. 
Citation: Md. Zafar Mahfooz Nomani et al, 2020. Access and Benefit Sharing Models of Biodiversity Conservation in International and Comparative Law Perspective Advances in Natural and Applied Sciences., 14(1): 1-13. DOI: 10.22587/anas.2020.14.1.1

[16] Nomani, M.Z.M. (2000). Environment Agriculture and Challenges of Bio-Piracy: A Blue Print of Indian Sui Generis Legal Order. Indian Journal of Environmental Law, 1(2),3-22.See also: Nomani, M.Z.M. \& Rahman F. (2011). Intellection of Trade Secret and Innovation Laws in India. Journal of Intellectual Property Right, 16(4):341-350.

[17] Nomani, M.Z.M. (1998).Water Pollution and Conservation Existing Legal Framework and Strategy for Reform', in Farooq A. Khan (ed.) Water Resource Development: Thrust and Challenges, Anmol Publication, New Delhi. [18] Swiderska, K. (2001). Developing the Philippines' Executive Order No. 247 on access to genetic resources (No. 4). IIED.

[19] Castro, N. T. (2000). Three Years of the Indigenous Peoples Rights Act: Its Impact on Indigenous Communities. Kasarinlan: Philippine Journal of Third World Studies, 15(2).

[20] Calanog, L.A., (1996). Indigenous Knowledge and Biodiversity Conservation. Canopy International and the Ecosystems Research and Development Bureau, Department of Environment and Natural Resources.

[20] Tolentino Jr, E. L. (2009). Philippines National Consultative Workshop to Identify Stakeholders and Capacity Building Needs in Forest Genetic Resources Conservation and Management. Forest Genetic Resources, 89.

[21]Government of the Philippines, (1995). Guidelines and Establishing a Regulatory Framework for the Prospecting of Biological and Genetic Resources, their by-products and derivatives, for Scientific and Commercial Purposes, and for Other Purposes. Executive Order 247.

[22] Government of the Philippines, (1997). Regulating Access to Biological and Genetic Resources in the Philippines: A Manual on the Implementation of Executive Order No. 247.

[23] Nomani, M.Z.M. (2010).Biological Diversity, IPR \&Sustainable Development: A Critical Appraisal of Access \& Benefit Sharing Models of U.S., Australia \& India', International Journal of Environmental Consumerism, 6(1\&2), 40-55.

[24] BNA, (1993). Biodiversity Protection Provided In International Pacts Seen As Best Framework ForBioprospecting. International Environments Daily, III: (30 June 1993).

[25] Joyce, C., (1992). Western Medicine Men Return To The Field. AIBS: 399-403.

[26] Department of Environment \& Energy (DoE\&E), (2017). Threatened Species Scientific Committee (TSSC): Guidelines For Nominating And Assessing The Eligibility For Listing Of Ecological Communities As Threatened According To The Environment Protection And Biodiversity Conservation Act 1999and The EPBC Regulations 2000: Australian Government[http://www.environment.gov.au/system/files/pages/d72dfd1a-f0d84699-8d43-5d95bbb02428/files/guidelines-ecological-communities.pdf]

[27] Burton, G., (2009). Access \& Benefit Sharing: ABS Law \& Administration In Australia, Revista Internacional de Direito e Cidadania, Australia 94.

[28] Amirmahmoudi, A., \& Nomani, M.Z.M. (2018). 'Access \& Benefit Sharing Provisions Under Biodiversity Conservation Law In Australia \& Its Implications For India’, Legal Research Development, 4(2), 35-46.

[29] Nomani, M.Z.M. (1997). Federalism under Indian Constitution: A Study of Environmental Law, Indian Bar Review, 24(1 \& 2),203-222.

[39]Bhutani, S. \& Kohli, K. (2012). Ten Years Of The Biological Diversity Act, Economic and Political Weekly, 1518

[31] Nomani, M.Z.M., (2001). WTO, TRIPS Agreement And Protection of Plant Variety: Imperatives And Implication for Indian Intellectual Property Regime In A.K. Kaul\& V.K. Ahuja (eds.), Law Relating To Intellectual Property Rights: Retrospect \& Prospect, University of Delhi, Delhi. Pp: 117-133.

[32] Nomani, M.Z.M. \& Rahman, F. (2016). Bio-Piracy of Traditional Knowledge Related Geographical Indications: A Select Study of Some Indian Cases. Manupatra Intellectual Property Reports (MIPR), 3(3),135-152.

[33] Ministry of Environment, Forest \& Climate Change (MoEF\&CC), (2017). Government of India, available at https://www.bsienvis.nic.in/Database/Biodiversity-Hotspots-in-India 20500.aspx (last visited on August 15, 2017).

[34] Nomani, M.Z.M. (2000). Laws \& Flaws Relating To Biological Diversity In India: A Kaleidoscopic View. Company Law Journal, II-J: 17-22.

[35] Ten Kate, K. \& Laird, S.A. (1999). Commercial Use of Biodiversity: Access To Genetic Resources And BenefitSharing, Earthscan, London.

[36] Kohli, K. \& Bhutani, S., (2015). Access to India's Biodiversity and Sharing Its Benefits, Economic \& Political Weekly, 50:1.

[37] Department of Biotechnology. (2007). National biotechnology development strategy 2007, Ministry of Science and Technology, Government of India, New Delhi See also: National Biodiversity Authority, (2013). Guidelines For Operationalisation Of Biodiversity Management Committees, National Biodiversity Authority, India. 
[38] Nomani, M.Z.M., Wani, M.R. \& Tahreem, M. (2019). Impact of Judicial Doctrine and Geo Spatial Technologies in Refinement of Environmental Impact Assessment Laws and Policies in India, International Journal of Recent Technology \& Engineering, 8(4): 8013-16.

[39] Nomani M.Z.M., (2018). Application of Trade Secret Law in Plant Variety Protection in India. Manupatra Intellectual Property Reports (MIPR), 2 (1),141-156.

[40] Nomani, M.Z.M. (2017). Legal Dynamics Of India's Science Technology \& Innovation Policy 2013 \& Intellectual Property Policy 2016, Manupatra Intellectual Property Reports (MIPR), 3(2),19-25.

[41] Kohli, K. \& Bhutani, S. (2017). 'Biodiversity and the Processes of Law', Sabu Abdulhameed, N.S. Pradeep \& Shiburaj Sugathan (Ed.) Bioresources and Bioprocess in Biotechnology: Status and Strategies for Exploration, Vol.1 Springer, Singapore, 49-71.

[42] Kohli, K. \& Bhutani, S. (2011). Chasing Benefits: A Post-Nagoya Protocol View on Access and Benefit Sharing, Briefing Paper, Kalpavriksh and World Wide Fund for Nature, Pune.

[43] Pushpangadan, P. et al. (1998). Arogyapacha' (TrichopuszeyalnicusGaertn), The 'Ginseng' of Kani Tribes of Agasthyar Hills (Kerala) for Evergreen Health and Vitality, Ancient Science of Life, 8(1),13-16.

[44] Utkarsh, G. (2001). People's Biodiversity Register For Access \& Benefit Sharing. National Biodiversity Strategy and Action Plan. Kalpavriksh, Pune, \& Ministry of Environment and Forests, Government of India, New Delhi. 